\title{
POLÍTICAS PÚBLICAS E MEIO AMBIENTE: O CASO DO MEXILHÃO DOURADO
}

\section{PUBLIC POLICY AND ENVIRONMENT : THE GOLDEN MUSSEL CASE}

\author{
Luíz Ricardo Santana de Araújo Júnior ${ }^{1}$ \\ Liziane Paixão Silva Oliveira ${ }^{2}$
}

\section{RESUMO}

O trabalho realiza uma análise da Força Tarefa Nacional de Controle do Mexilhão Dourado e do Plano de Ação Emergencial, considerados políticas públicas ambientais. A pesquisa bibliográfica, com o uso de fontes primárias e secundárias, faz uma abordagem conceitual da bioinvasão pelo Mexilhão Dourado. Após, realiza-se a análise das características gerais da Força Tarefa Nacional e do Plano Emergencial, apontando-se as inconsistências encontradas, seja no planejamento ou na implementação da política, como base para uma análise da eficácia da política ambiental. Por fim, são analisadas possíveis formas de evitar o aparecimento das inconsistências encontradas no caso do Mexilhão Dourado.

Palavras-chave: bioinvasão; Mexilhão Dourado; Política Pública Ambiental; Força Tarefa Nacional; Eficácia.

\begin{abstract}
The papper carries out an analysis of the National Task Force Control of Golden Mussel and Emergency Action Plan, which are considered environmental policies. The bibliographical research, using primary and secondary sources, make a conceptual approach to bioinvasion the Golden Mussel. Then it perfomes analysis of the general characteristics of the National Task Force and the Emergency Plan, pointing to inconsistencies that were found, either in the planning or implementation of policy, as a basis for an analysis of the environmental policy effectiveness. Finally, they analyse possible ways to avoid the appearance of inconsistencies that were found in the case of Golden Mussel.
\end{abstract}

Keywords: bioinvasion; Golden Mussel; Environmental Public Policy; Task Force National; Efficiency.

\footnotetext{
Mestrando em Direitos Humanos pela Universidade Tiradentes - UNIT, Aracaju, Sergipe, (Brasil). Assessor Jurídico do MPU. Pesquisador do Grupo de Pesquisa Novas Tecnologias e o Impacto nos Direitos Humanos UNIT - CNPq. E-mail: luizraraujo@ mpf.mp.br

2 Doutora em Direito pela Université Paul Cézanne Aix-Marseille III. Coordenadora do Mestrado em Direitos Humanos - UNIT. Líder do Grupo de Pesquisa: Novas Tecnologias e o Impacto nos DH. E-mail: liziane_paixao@unit.br
} 


\section{INTRODUÇÃO}

O Mexilhão Dourado, cientificamente denominado Limnoperna fortunei, é um molusco bivalve originário do sudeste asiático, que foi identificado na América do Sul, pela primeira vez, no ano de 1991, na Argentina, na bacia do Rio do Prata. Dispersando-se normalmente associado ao trânsito de embarcações, o Mexilhão foi registrado no Brasil em 1998, inicialmente, na região do Pantanal-Matogrossense, hoje, podendo ser encontrado em diversas localidades como a região de Porto Alegre e a Lagoa dos Patos, a região de Uruguaiana, a região de Curitiba, o Oeste de São Paulo e do Paraná (MANSUR et al., 2003, p. 75-84).

O presente trabalho analisa a Força Tarefa Nacional de Controle do Mexilhão Dourado, enquanto política pública, abordando, inicialmente, o processo de bioinvasão e de caracterização do Mexilhão Dourado como espécie exótica invasora. Em um momento posterior, indica-se, no caso em análise, quais os problemas da Força Tarefa e, quando possível, apontamse estratégias que possam ser adotadas em casos congêneres para inviabilizar o surgimento dos mesmos problemas ambientais.

Assim, na primeira parte do estudo, foi exposto o conceito de espécie exótica invasora, da mesma forma que o processo conhecido como bioinvasão, uma vez que tanto o processo quanto o conceito são necessários para a compreensão do Caso Mexilhão Dourado como espécie exótica invasora, bem como a necessidade de que, de fato, uma política pública voltada ao seu combate tenha sido elaborada.

Considerando a dimensão nacional do problema, foi escolhido o caso de Ilha Solteira, no estado de São Paulo, em virtude da sistematização das informações no curso da ação civil pública de $\mathrm{n}^{\circ}$ 0000764-05.2012.4.36124 e do inquérito civil de $\mathrm{n}^{\circ}$ 1.34.030.999156/2009-46, bem como por ser um exemplo com características relevantes para o estudo.

Num segundo momento, foram estudadas as atividades desenvolvidas pela Força Tarefa Nacional de Combate ao Mexilhão Dourado, identificando os seus atores, seus objetivos, suas atividades com o intuito de verificar a sua efetividade. A título de considerações finais é realizada uma breve análise do caso a luz das políticas públicas, com o objetivo de identificar quais as causas das falhas apontadas e se há formas de minimizá-las em casos idênticos ou mesmo de eliminá-las em futuras atuações semelhantes. Para a sua realização a pesquisa se baseou em um levantamento bibliográfico e jurisprudencial. 


\section{CONHECENDO E CLASSIFICANDO O MEXILHÃO DOURADO}

Há no âmbito internacional o reconhecimento de que a introdução de espécies que não fazem parte de determinado nicho ecológico representa um problema para o meio ambiente em escala global.É nesse sentido que a Convenção das Nações Unidas sobre Diversidade Biológica - CDB, em seu artigo oitavo, aponta a obrigação dos seus signatários ${ }^{3}$ de "impedir que se introduzam, controlar ou erradicar espécies exóticas que ameacem os ecossistemas, habitats ou espécies” (CDB, 1992, p. 214). A inquietude positivada na convenção advém da preocupação com a perda da diversidade biológica, ou biodiversidade, que tomou conta do cenário internacional e fez parte, inclusive, das disposições do preâmbulo convencional, que afirmou estarem as partes atentas para "com a sensível redução da diversidade biológica causada por determinadas atividades humanas" (CDB, 1992, p. 211).

A preocupação externada pelas Nações $\operatorname{Unidas}^{4}$ encontra ressonância na literatura, uma vez que, como observa Landry (2004, p.9), a ação humana ensejou um aumento substancial do fenômeno natural que é a bioinvasão ou invasão biológica e, em consequência, transformou um fato natural em um problema globalizado.

A leitura do texto convencional impõe, no entanto, a necessidade de diferenciação entre uma espécie exótica e uma espécie exótica invasora. Embora ambos os organismos possam ser considerados estrangeiros em relação a um ambiente, em uma interpretação da CDB, pode-se afirmar que nem toda espécie exótica ameaça alguma espécie ou algum ecossistema, sendo necessária a intervenção apenas quando a ameaça ocorrer. Assim, fica claro que a presença de uma espécie fora do seu local de origem não a classifica imediatamente como perigosa.

Landry (2004, p.6) identifica algumas etapas para a caracterização de uma invasão biológica, ou seja, para que a espécie estrangeira, denominada exótica, possa ser considerada invasora e, assim, tachada de ameaçadora. O quadro abaixo indica as etapas elencadas pelo autor.

Quadro 1. Etapas de uma bioinvasão

\footnotetext{
${ }^{3} \mathrm{O}$ Brasil assinou e ratificou a referida convenção, tendo inclusive a transformado em decreto, de forma que está submetido a suas diretrizes.

${ }^{4} \mathrm{O}$ agravamento dos problemas ambientais levou as Nações Unidas a se debruçar sobre o tema da perda da biodiversidade, enquanto problema ambiental, dado que a organização, por meio dos seus estudos e relatórios constatou o gradativo aumento daquela perda.
} 
Passo 1: o organismo está presente em seu ambiente original

Passo 2: o organismo sobrevive durante o transporte e à chegada em um novo ambiente

Passo 3: o organismo se instala no novo ambiente

Passo 4: o organismo passa por um tempo de incubação, no qual há poucos indivíduos

Passo 5: os indivíduos se espalham no novo ambiente

Passo 6: o organismo causa impactos ambientais

Passo 7: o organismo causa impactos nos seres humanos

Fonte: LANDRY, Jean-Sébastien. La bioinvasion: une menace qui nécessite un plan d'action québécois. 62 p. Dissertação (Mestrado em Meio Ambiente). Université de Sherbrooke, Québec, Canada, jun. 2004. Disponível em: <www.jslandry.netne.net/essai.pdf>. Acesso em 16 de nov. 2015.

Consoante o quadro, nas três primeiras etapas, tem-se a presença do organismo em seu hábitat originário; o seu transporte, que pode ocorrer naturalmente, mas que hoje é bastante afetado pelas ações humanas e, por fim, a instalação do organismo no novo ambiente. Em seguida, a espécie passa por um processo de adaptação e incubação, fase na qual o autor ressalta que, ainda, há uma pequena quantidade de indivíduos, para então ocorrer a expansão populacional, que desembocará em impactos ecológicos e impactos, também negativos, ao ser humano.

Ressalta-se que, mesmo diante da necessidade de observação de influências negativas para que se classifique determinada espécie como invasora, não há necessidade de que os impactos ocorram cumulativamente, ou seja, a sua existência, mesmo que não enseje nenhum dano direto ao ser humano já possui o condão caracterizador da periculosidade da espécie.

A União Internacional para a Conservação da Natureza - UINC (OTERO, 2013, p.8) afirma que as espécies exóticas invasoras são espécies exóticas que, uma vez estabelecidas em ecossistemas naturais ou semi-naturais, tranformam-se em vetores de modificação de tais meios, tornando-se abundantes, com elevado aumento populacional, ao ponto de representarem uma ameaça à diversidade biológica nativa. Otero $(2013$, p.8) aponta, ainda, algumas características que fazem das espécies exóticas invasoras, tais como, a sua capacidade de prosperar em ambientes com características distintas e a tolerar uma grande diversidade de condições ambientais, e, ainda, grandes taxas de crescimento e reprodução, a ausência de predadores naturais e uma alta capacidade de explorar diferentes fontes de alimentação.

A identificação de uma espécie como invasora, no entanto, não é fácil. Landry (2004, p.7) admite que mesmo com o avanço tecnológico é difícil prever se determinada espécie será ou não invasora. Da mesma forma, Otero $(2013$, p.9) afirma que, em razão da necessidade de que a espécie enfrente todo um processo até que chegue à fase invasora, é bastante difícil a 
previsão acerca do potencial invasor. Nesse sentido, a Otero (2013, p.9) aponta, como alternativa para a identificação da capacidade invasiva, a conformação da sua condição de espécie expotica invasora em outros locais onde tal espécie seja encontrada no mundo, com a consequente análise do comportamento da espécie em outros locais do globo, numa verificação dos impactos da sua presença.

Em consequência das suas características intrínsecas, as espécies exóticas invasoras geram uma série de impactos seja sobre o meio ambiente, sobre a economia, sobre a saúde e o bem-estar humano ou, ainda, impactos culturais (DE POORTER, 2009, p.5).

Os impactos ambientais são caracterizados pela perda da biodiversidade, advinda da predação dos invasores sobre as espécies nativas, da diminuição de espaço para as espécies locais, pela diluição genética causada pela hibridação; os impactos diretos à saúde e ao bemestar humano se verificam pela presença de parasitas e doenças, ao passo que os impactos econômicos são identificados a partir da interferência da espécie exótica invasora nas atividades de pesca, assim como nos custos oriundos das ações de controle, limpeza e quarentena das áreas afetadas. Os impactos culturais, por sua vez, podem ser observados com a supressão de determinada espécie nativa que fazia parte dos usos e costumes de uma comunidade (DE POORTER, 2009, p.5).

O caso do Mexilhão Dourado, originário do sudeste asiático e introduzido por meio dos processos de captação e troca da água de lastro $^{5}$ na bacia do Rio do Prata, amolda-se às características de uma bioinvasão. Os estudos e as manifestações presentes no inquérito civil $n^{\circ}$ 1.34.030.000156/2009-46 levaram o Ministério Público a apontar algumas características do Limnoperna fortunei, conhecido como Mexilhão Dourado:

Quadro 2. Características do Mexilhão Dourado no Reservatório de Ilha Solteira/SP

Ausência de predadores naturais;

Alto poder reprodutivo;

Grande mobilidade das larvas.

Fonte: MPF. Inquérito Civil nº 1.34.030.000156/2009-46. 2014. Procuradoria da República em Jales/SP.

Da mesma forma, foram indicados alguns impactos negativos oriundos da presença do Mexilhão Douradonas águas do Reservatório de Ilha Solteira/SP:

\footnotetext{
${ }^{5}$ A Convenção Internacional sobre Controle e Gestão da Água de Lastro e Sedimentos de Navios apresenta o conceito da água de lastro como sendo a água com suas partículas suspensas levada a bordo de um navio para o controle do trim, banda, calado, estabilidade ou tensões do navio.
} 
Quadro 3. Consequências negativas advindas do Mexilhão Dourado

Extinção de espécies nativas de moluscos;

Alterações no bioma do Rio Paraná;

Contaminação da água;

Entupimento de tubulações e filtros, causando problemas no abastecimento de água, na irrigação e na geração de energia;

Efeitos negativos para a produção pesqueira.

Fonte: MPF. Inquérito Civil no 1.34.030.000156/2009-46. 2014. Procuradoria da República em Jales/SP.

Dessa forma, a identificação das características e dos efeitos do Mexilhão Dourado permitem a classificação da espécie como exótica invasora, demandando, assim, do poder público e da sociedade civil a atuação rápida e eficiente a fim de evitar a perpetuação dos efeitos negativos em todos os seus aspectos.

A água de lastro, especificamente, é alvo da atenção da Comunidade Internacional que, convicta do potencial negativo das espécies exóticas invasoras e munida de dados que possibilitam a identificação dos vetores de introdução daquelas espécies, elaborou a Convenção Internacional sobre Controle e Gestão da Água de Lastro e Sedimentos de Navios, no ano de 2004, por meio da qual os Estados reconheceram "que a transferência e introdução de Organismos Aquáticos Nocivos e Agentes Patogênicos através da Água de Lastro dos navios ameaça a conservação e uso sustentável da diversidade biológica" e estipularam uma série de obrigações visando "a prevenir, minimizar e, por fim, eliminar os riscos ao meio ambiente, à saúde pública, às propriedades e recursos" oriundos da introdução de espécies exóticas, pelo vetor específico que é a água de lastro (ONU, 2004).

\section{A FORÇA TAREFA NACIONAL PARA CONTROLE DO MEXILHÃO DOURADO}

Reconhecendo o problema da bioinvasão provocado pelo Mexilhão Dourado, o Governo Federal brasileiro, por meio do Ministério do Meio Ambiente, editou a Portaria n ${ }^{\circ} 494$, de 22 de dezembro de 2003, através da qual se criou a Força Tarefa Nacional para Controle do Mexilhão Dourado - FTN.

Conforme previsão do artigo $2^{\circ}$ da aludida portaria, a Força Tarefa foi composta, inicialmente, pelos seguintes órgãos públicos:

Quadro 4. Composição estatal da Força Tarefa Nacional 


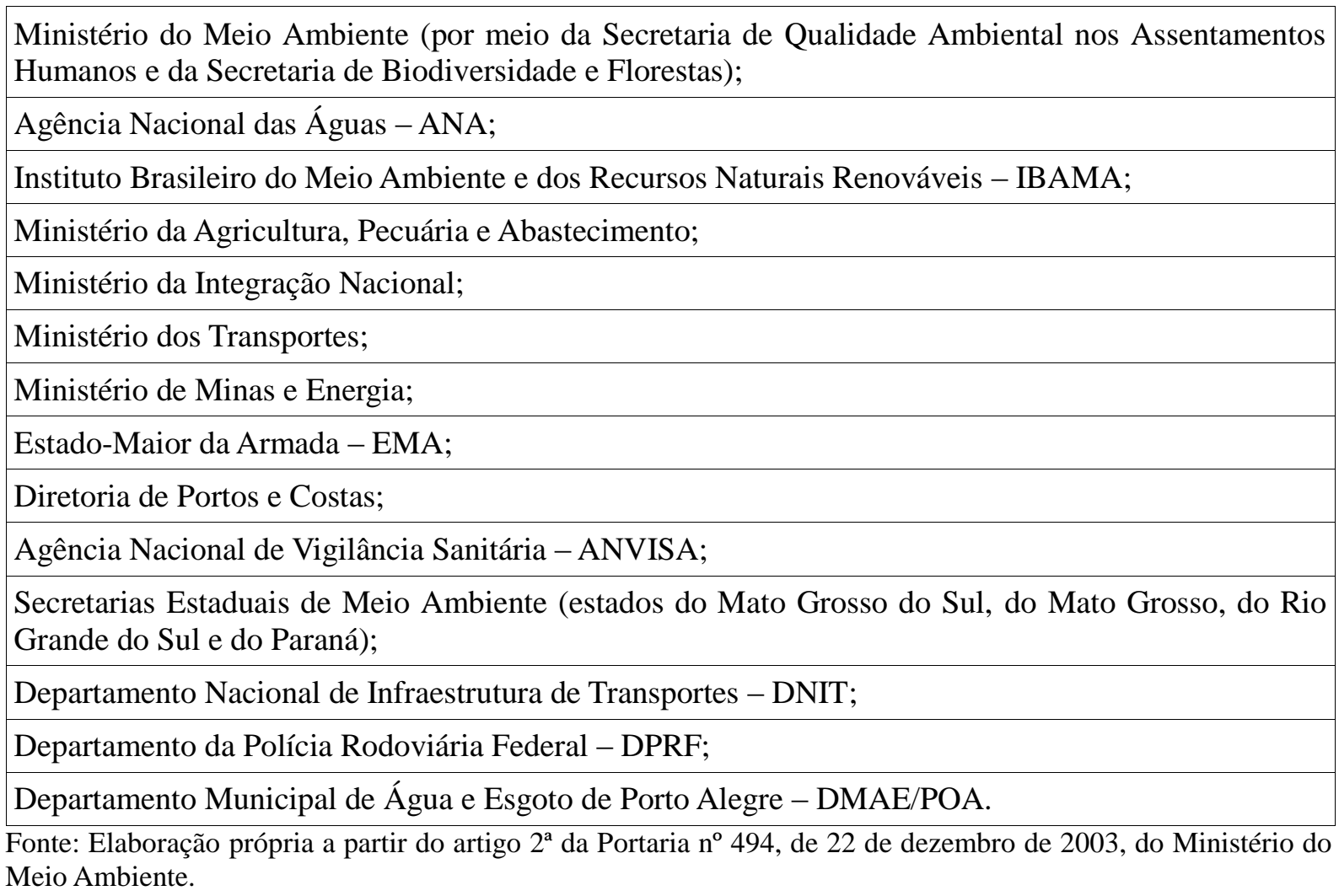

Além dos entes e órgãos públicos designados, a sociedade civil participou, desde o surgimento da FTN, por meio das seguintes entidades:

Quadro 5. Composição civil da Força Tarefa Nacional

\begin{tabular}{|l|}
\hline Associação Brasileira das Empresas Geradoras de Energia Elétrica - ABRAGE; \\
\hline Centrais Elétricas Brasileiras S.A. - ELETROBRÁS; \\
\hline Itaipu Binacional; \\
\hline Furnas Centrais Elétricas S. A.
\end{tabular}

Fonte: Elaboração própria a partir do artigo $2^{\mathrm{a}}$ da Portaria n ${ }^{\circ} 494$, de 22 de dezembro de 2003, do Ministério do Meio Ambiente.

A portaria criadora da Força Tarefa, que contou com apenas oito artigos, instituiu como finalidade a avaliação comportamental do Mexilhão Dourado, considerando-o como organismo invasor; a identificação dos vetores de dispersão do organismo em águas interiores sob a jurisdição brasileira, além de medidas de controle da espécie, para impedir o seu avanço e a sua concentração no Brasil.

Como um dos primeiros resultados práticos da FTN, foi criado o Plano de Ação Emergencial, em 2004, que decorreu "da evidente situação de risco ecológico e socioeconômico determinado pela já abrangente dispersão do mexilhão dourado em águas brasileiras.”(MMA, 
2004, p. 02). A adoção de ações de caráter emergencial, nesse sentido, está atrelada à existência do processo de bioinvasão em diversos corpos hídricos do sul e do sudeste brasileiro, com consequências negativas para a pesca e a geração de eletricidade nas regiões afetadas, sem deixar de lado o intrínseco dano ambiental do processo biológico.

No que se chama de Processo de Planejamento (Oliveira, 2006, p. 280), foram estabelecidas quatro estratégias para a execução do Plano Emergencial. Assim, com foco nos vetores de introdução e dispersão do Mexilhão Dourado, a Plano Emergencial dividiu suas atividades em "Divulgação, Capacitação, Monitoramento e Fiscalização" (MMA, 2004, p. 02).

De acordo com o Plano Emergencial, o componente Divulgação representa item de importância ímpar para os esforços empreendidos, na medida em que possibilita o envolvimento dos diversos setores da sociedade, além de possuir, também, um caráter sensibilizador, uma vez que funciona como difusor dos "problemas provenientes da invasão do mexilhão dourado e de procedimentos básicos para favorecer a sua contenção nas áreas já infestadas" (MMA, 2004, p. 03). Representando ponto de importância ímpar na medida em que possibilita a participação da sociedade civil na implementação de toda a política pública, auxiliando de igual modo na própria prática dos atos, uma vez que em pontos específicos a ação da sociedade é importante na transposição da política pública do plano teórico para o plano fático.

O elemento Monitoramento, que segundo o Plano Emergencial possui caráter eminentemente qualitativo, foi pensando como angariador de dados sobre o organismo e as áreas do território brasileiro onde há infestação. De igual modo, foi criado para a acompanhar o processo de dispersão e para servir de orientação na tomada de ações preventivas de fiscalização (MMA, 2004, p. 03).

O item capacitação foi concebido com o escopo de munir os agentes do conhecimento necessário para atuar e compreender a situação. A descrição do componente pelo Plano Emergencial aponta para a preocupação com o preparo dos promotores das ações idealizadas:

A Capacitação tem como propósito, em caráter geral, ampliar a formação de técnicos em conceitos e fundamentos aplicados para ocorrência do mexilhão dourado e para os problemas associados em ecossistemas aquáticos naturais, artificiais e instalações industriais, bem como, em caráter específico, fornecer os conceitos básicos para identificação e controle do molusco nas várias fases da vida, relacionados à biologia e ecologia da espécie e os impactos ambientais e econômicos causados pelo invasor (MMA, 2004, p. 03).

O último componente estrutural do Plano Emergencial, a Fiscalização, consiste numa série de procedimentos destinados a conter a disseminação da espécie invasora nos corpos 
hídricos ainda não contaminados. Há o estabelecimento da diretriz de que a fiscalização deve considerar todas as formas de introdução e dispersão do mexilhão. No entanto, o próprio plano aponta o transporte "por incrustação em partes das embarcações em contato com a água ou, ainda como forma larval, em depósitos de água, viveiros de isca" como principal vetor, merecendo maior atenção (MMA, 2004, p. 04).

Além disso, foram estipuladas quatro áreas para a atuação do Plano Emergencial, quais sejam: Região de Porto Alegre e Lagoa dos Patos, Região de Uruguaiana, Região de Curitiba e Região do Pantanal e Oeste de São Paulo e Paraná (MMA, 2004, p. 03).

Da análise da Força Tarefa Nacional para Controle do Mexilhão Dourado e do Plano Emergencial, criado para efetivar as medidas pretendidas pela FTN, percebe-se que ambas as ações amoldam-se de maneira satisfatória ao conceito de políticas públicas apresentado por Rodrigues (2013, p.13), na medida em que apresentam-se, de fato, como um "processo pelo qual diversos grupos que compõem a sociedade [...] tomam decisões, que condicionam o conjunto dessa sociedade".

Pode-se ir mais longe, na esteira da classificação, e indicar a FTN e o Plano Emergencial como políticas públicas ambientais, componentes da gestão integrada de recursos, abordagem, que segundo Peccatiello (2011, p.73) é fruto de um processo de evolução das políticas ambientais, não mais focado apenas em administrar o uso dos recursos naturais ou voltada apenas para o controle da poluição.

A sua classificação, no entanto, não afasta os seus problemas de planejamento e de implementação (OLIVEIRA, 2006, p. 277), que acabam por implicar em notável redução da eficácia da política. No caso da FTN e do Plano Emergencial três são os problemas apontados pelo Ministério Público Federal e que motivaram, é certo, a propositura da ação civil pública de $n^{\circ}$ 0000764-05.2012.4.36124.

O primeiro problema indicado reside no plano do planejamento. A área de atuação da Força Tarefa não engloba toda a Bacia do Prata. Foram definidas quatro regiões para a atuação emergencial, no entanto, mesmo em uma análise menos detida verifica-se a insuficiência da referida delimitação geográfica para alcançar os próprios objetivos do plano, em especial a prevenção da disseminação da espécie invasora para o restante dos corpos hídricos brasileiros. Todos os estados brasileiros componentes da Bacia do Prata (São Paulo, Paraná, Mato Grosso, Mato Grosso do Sul, Minas Gerais, Goiás, Distrito Federal, Santa Catarina e Rio Grande do Sul), para que se alcançasse o objetivo da prevenção, deveriam constar no plano de ação. A identificação das áreas ainda não afetadas em tais estados e o planejamento para que tais áreas 
continuassem livres do organismo invasor, também, deveria ter feito parte do planejamento.

A segunda inconsistência da política pública ambiental diz respeito a ausência do caráter preventivo. Pois, em que pese a existência da prevenção no plano emergencial, a criação da FTN só ocorreu após graves consequência socioambientais e socioeconômicas, reconhecidas pelo governo brasileiro, como se observa do "considerando" da Portaria 494, de 22 de dezembro de 2003: "Considerando as consequências ambientais e socioeconômicas causadas pela invasão do Limnoperna fortunei (mexilhão dourado), que se espalha pelas águas interiores nacionais, a partir do Rio Grande do Sul, da Bacia do Prata e do Pantanal-Matogrossense" (MMA, 2003, p.01).

O ponto é de bastante relevância, pois uma vez se tratando de política pública de caráter ambiental, significa dizer que estará submetida, na medida do possível, aos princípios que regem o direito ambiental, dentre os quais despontam a prevenção (SARLET, 2014, p. 164), que impõe a adoção de medidas para impedir a concretização de danos conhecidos, como é o caso da bioinvasão pelo Mexilhão Dourado.

Assim, a adoção de uma política pública bem planejada, deveria ter ocorrido tão logo fosse identificada a presença da espécie exótica invasora, a fim de impedir os ciclos de reprodução e propagação, sem tardar na resolução de um problema, que por suas características peculiares, tende apresentar crescimento progressivo.

O terceiro ponto, que pode ser apontado como resultado da soma de inconsistências, refere-se à ausência de eficácia da FTN, que foi constata pelo MPF, na propositura da ação civil pública, uma vez que passados aproximadamente oito anos da implementação da política o estado de infestação na região de Ilha Solteira/SP era alarmante.

A constatação da terceira inconsistência serviu para a confirmação das duas premissas anteriores. A primeira no sentido de que não foi estabelecido um perímetro adequado ao combate efetivo da propagação do Mexilhão Dourado, a segunda ligada ao fato de que apenas após a propagação sistemática da espécie exótica invasora é que foram adotadas providências, quando a perda de biodiversidade já estava caracterizada em várias das regiões afetadas afligindo a área a ponto de afetar a população, causando verdadeiro problema social intimamente ligado com problemas econômicos.

\section{A EFICÁCIA DA POLÍTICA PÚBLICA}

As inconsistências apontadas são ao mesmo tempo causa e consequência dos impactos 
negativos na eficácia da política pública ambiental aqui analisada. O processo de planejamento da FTN e do Plano Emergencial aparentemente repetiu o caminho percorrido na elaboração de outras políticas públicas ambientais que não deram certo. Um processo de total desvinculação entre o planejamento e a implementação, que acaba por criar um vácuo entre as fases, que de fato devem ser pensadas como uma única coisa (OLIVEIRA, 2006, p.276). A elaboração de um plano que não pode ser implementado, ou que deveria ser implementado de forma diversa do planejado acarreta, como no caso da FTN, sérios problemas tanto de caráter socioeconômico como socioambientais.

No caso das políticas públicas ambientais, especificamente daquelas que tratam da biodiversidade, o Brasil enfrenta uma série de problemas para garantir o correto equacionamento entre exploração e conservação, a exemplo do que ocorre com a Amazônia Azul e a série de dificuldades para se garantir a proteção da biodiversidade e a gestão durável dos recursos (BARROS et all, 2015, p.209).

Nesse sentido, problemas de planejamento e implementação, que implicam na ineficácia de políticas públicas gerais, provocam, no caso das políticas públicas ambientais, o agravamento dos danos ao meio ambiente, que por suas próprias características tendem a ser de difícil reversibilidade e, em alguns casos, possuem caráter de irreversibilidade. Para fins deste trabalho, a eficácia é entendida como o dever da administração pública de prestar os serviços e desenvolver as ações da maneira adequada, para que, assim, tais atos atendam aos fins a que se destinam, em atendimento ao princípio da eficiência, estabelecido constitucionalmente e que deve ser seguido pela Administração Pública, na elaboração e na implementação das políticas públicas (DI PIETRO, 2016, p. 84).

A FTN se mostrou ineficaz na medida em que não abrangeu toda a área necessária para conter a disseminação da espécie invasora, assim como não foi proposta de forma a contemplar adequadamente a prevenção ambiental.

A política que aparentemente demonstra uma articulação entre diversos atores públicos e privados, acabou por demonstrar ser ineficiente, pois para sua eficácia acabou dependendo da intervenção do Ministério Público Federal.

Como alternativa para a ausência de eficácia da política pública, aponta-se a contribuição social, seja de forma organizada, num verdadeiro associativismo, seja de forma um pouco menos organizada por meio de uma participação difusa.

Lüchmann (2014, p. 172) aponta o associativismo na sociedade civil como um importante mecanismo para um atuação da sociedade "mais cooperativa junto aos governos, 
contribuindo para avaliar, propor e deliberar sobre políticas públicas por meio de processos pautados na participação e na estabilização de conflitos". Nesse sentido, uma participação de caráter associativista no caso da FTN poderia proporcionar o adequado planejamento para a delimitação da área, por exemplo, uma vez que a divulgação e a capacitação, objetivos do próprio Plano Emergencial, articulados ao associativismo poderiam resultar em ações mais eficazes.

Ainda que não seja aplicado à sociedade civil, a autora aponta benefícios do associativismo quando aplicados à sociedade de forma genérica ou direcionado a movimentos sociais, uma vez que a maior participação do cidadão e a promoção de mudanças nas relações de poder advindas dessa participação consciente, promovem uma melhora na qualidade da representação política, redundando em um accountability dos novos representantes (LÜCHMANN, 2014, p. 169;172).

Oliveira (2006, p. 281) conceitua o accountability a como "capacidade de resposta institucional", ou seja, a capacidade de prestar contas dos governantes para com os governados. Garantindo, dessa forma, uma maior eficácia da política pública, na medida em que há possibilidade de maior cobrança por parte da sociedade e reparo de arestas, por ventura, identificadas com as cobranças.

Gohn (2014, p. 78) identifica uma repolitização da sociedade brasileira, que perpassa pela atuação da sociedade civil em movimentos sociais, entidades sem fins lucrativos e conselhos, programas, políticas sociais, que favorecem a retomada do associativismo e, por consequência, a formação de um sentimento de necessidade da resposta da administração pública, no tocante à execução de políticas públicas ambientais.

A mesma autora aponta como exemplo a democratização da gestão como forma de legitimação das instituições (GOHN, 2014, p. 78). Ressalte-se que como "expressão da autoridade soberana do poder público", as políticas públicas carecem dessa legitimidade, que pode ser atribuída com a maior participação popular (RODRIGUES, 2013, p. 14).

Assim, a participação social apresenta ganhos variados sequenciais às políticas públicas. Um que permite o planejamento de todos os instrumentos da política de forma mais adequada à realidade; dois que, em consequência de um planejamento adequado, permite uma maior eficácia no plano da implementação; três que, por meio do accountability garante a possibilidade de revisão das políticas inadequadamente elaboradas ou a modificação na forma de execução das mesmas garantindo a sua eficiência, ao mesmo tempo em que, ao transportar o cidadão para o papel de ator protagonista das políticas públicas, lhes outorga a legitimidade 
que, por vezes, carece aos atos do poder executivo no contexto político brasileiro.

Por fim, em se tratando de políticas públicas de caráter ambiental, há necessidade de releitura das ações a serem promovidas, de forma que se levem em consideração as características intrínsecas do meio ambiente e, por conseguinte, dos seus princípios. Principalmente da prevenção e da precaução, princípios norteadores do direito ambiental e que visam impedir que danos irrecuperáveis acometam o meio ambiente, garantindo a articulação de ideias e a promoção de ações hábeis a identificar quais as áreas de maior suscetibilidade de propagação do organismo invasor, por exemplo, e fazendo atuar, também, nessas áreas os instrumentos das políticas públicas a serem desenvolvidos.

Há necessidade, portanto, de que em políticas públicas ambientais haja a vinculação entre o planejamento e a implementação, de forma que não se planeje algo além o aquém daquilo que se precisa implementar. Da mesma forma, impõe-se um olhar mais atento às características específicas de cada política pública que se pretende executar, favorecendo, dessa forma, a presença de caracteres indispensáveis, como é a prevenção e a precaução, quando se fala em política ambiental. Tudo isso como forma de objetiva um desempenho que possa ser classificado como eficaz e que dispense, portanto, a atuação de outras instituições governamentais de controle, como ocorreu com a FTN e o MPF.

\section{CONSIDERAÇÕES FINAIS}

A preocupação com os processos de bioinvasão é plenamente justificável, dado que já se tem como certa a influência negativa de tais processos sobre a diversidade biológica mundial, acarretando em sua diminuição. Como dito em linhas pretéritas, os impactos dos processos de invasão biológica são grandes e podem ser considerados como a segunda maior causa de perda de biodiversidade.

No Brasil há a incidência de alguns processos de bioinvasão, dentro os quais se destaca o caso do Mexilhão Dourado, espécie exótica invasora que adentrou nas águas territoriais brasileiras por meio da Bacia do Rio Prata e se disseminou por vários estados, causando problemas de ordem ambiental, de ordem social e de ordem econômica.

O Governo brasileiro, em ato de reconhecimento da situação crítica advinda da disseminação, elaborou, por meio do Ministério do Meio Ambiente, a Portaria nº 494, de 22 de dezembro de 2003, por meio da qual se criou a Força Tarefa Nacional para Controle do 
Mexilhão Dourado.

Como resultado da Força Tarefa foi elaborado o Plano de Ação Emergencial, composto por várias entidades públicas e privadas, que possuía quatro áreas de atuação (divulgação, capacitação, monitoramento e fiscalização), assim como delimitação geográfica (região de Porto Alegre e Lagoa dos Patos, região de Uruguaiana, região de Curitiba, região do Pantanal, Oeste de São Paulo e Paraná).

No entanto, como política pública ambiental tanto a Força Tarefa, quanto o Plano Emergencial apresentaram algumas inconsistências que foram abordadas ao longo do presente estudo, tais como a inadequação do planejamento, uma vez que a área de ação apresentou-se muito aquém daquela onde havia necessidade de atuação da Força Tarefa; ausência de caráter preventivo, dado que apenas após atingir um estado crítico de degradação ambiental, que desaguaram em uma série de impactos econômicos, é que se promoveu a política pública.

Ademais, a ausência de eficácia figura, também, como inconsistência da política analisada, sendo, em verdade, consequência das problemáticas anteriores. De fato, após anos de execução da política pública ambiental não se constatou a diminuição do processo de dispersão do mexilhão, ao contrário, verificou-se o aumento da sua incidência em certas áreas, a exemplo de Ilha Solteira/SP, fato que motivou a propositura de ação civil pública, por parte do Ministério Público Federal, por meio da qual o aludido órgão objetivou a participação da região atingida na área de atuação da Força Tarefa, como forma de garantir a eficácia das ações adotadas pela política.

Dessa forma, a fim de evitar problemas no processo de confecção, assim como problemas de eficácia em políticas públicas congêneres, identificou-se ações que podem ser adotadas para frear o insucesso de tais políticas, ou ao menos garantir uma melhor adequação das políticas públicas às problemáticas ambientais, que possuem características tão particulares. A primeira observação é a necessidade de que o planejamento esteja atrelado à implementação, o que significa dizer que devem ser formuladas as ações com devido cuidado para que não se crie um plano além ou aquém do necessário para tratar do problema a ser enfrentado pela política pública. Evitando-se, assim, a criação de um plano adequado, mas que não seja aplicado a toda a área de incidência da problemática, como ocorreu no caso do Mexilhão Dourado.

A segunda observação está vinculada diretamente à questão ambiental, uma vez, que estando diante de políticas públicas ambientais, é recomendado que tais políticas sejam criadas a partir da conjunção entre os princípios ambientais e as características peculiares das políticas públicas. Adequado, portanto, que tais instrumentos sejam criados em momentos oportunos, a 
fim de que seja respeitado o princípio da prevenção, sob pena de tais políticas públicas serem ineficazes, já que se deve ter em mente que os danos ambientais são progressivos e, uma vez concretizados, tornam o retorno ao estado inicial praticamente impossível.

A terceira recomendação está atrelada à participação social. A modificação do paradigma de participação da sociedade civil, no âmbito das políticas públicas ambientais, pode auxiliar na sua concretização, posto que o processo de modificação da qualidade representativa implica na formação de representantes mais preocupados com o accountability, possibilitando, assim, uma maior cobrança por parte dos atores sociais, caso seja verificada a ineficácia da política desenvolvida ou, ainda, a necessidade de sua adequação.

Assim, é imperioso que se produzam políticas públicas ambientais adequadas ao contexto de sua aplicação, que envolvam a totalidade da área afetada e, também, as áreas passíveis de infecção, garantindo-se o respeito à principiologia ambiental. Além disso, é necessário que se permita e se efetive um controle social da execução das políticas públicas de caráter ambiental, maximizando-se, dessa forma, as chances de que se possa alcançar a eficácia de tais instrumentos.

\section{REFERÊNCIAS}

BRASIL. Convenção sobre Diversidade Biológica - CDB. In Legislação de direito internacional. Obra coletiva de autoria da Editora Saraiva com a colaboração de Antônio Luiz de Toledo Pinto, Márcia Cristina Vaz dos Santos Windt e Lívia Céspedes. 4. ed. São Paulo: Saraiva, 2011.

BARROS, Jorge Gomes do Cravo; BARROS-PLATIAU, Ana Flávia ; COSTA DE OLIVEIRA, Carina ; OLIVEIRA, Liziane Paixao Silva. «Amazonie bleue » et projection brésilienne sur l'avenir. Outre-Terre, v. 42, p. 204-212, 2015.

DE POORTER, Maj. Menace en mer: les espèces exotiques envahissantes dans l'environnement marin.30 pages. UICN. Génève, Suisse: åtta design sàrl, 2009.

DI PIETRO, Maria Sylvia Zanella. Direito Administrativo. 29 ed. rev. atu. ampl. São Paulo: Forense, 2016. 
GOHN, Maria da Glória. Pluralidade da representação na América Latina. Revista Sociedade e Estado. vol. 29. nº 1, p. 78-90. jan./abr. 2014.

GOHN, Maria da Glória. A sociedade brasileira em movimento: vozes das ruas e seus ecos políticos e sociais. Caderno CRH, Salvador, vol. 27, nº 71, p. 431-441, mai./ago. 2014.

LANDRY, Jean-Sébastien. La bioinvasion: une menace qui nécessite un plan d'action québécois. 62 p. Dissertação (Mestrado em Meio Ambiente). Université de Sherbrooke, Québec, Canada, jun. 2004. Disponível em: <www.jslandry.netne.net/essai.pdf>. Acesso em 16 de nov. 2015.

LÜCHMANN, Lígia Helena Hahn. Abordagens teóricas sobre o associativismo e seus efeitos democráticos. Revista Brasileira de Ciências Sociais. vol. 29. nº 85. jun. 2014.

MANSUR, M. C. D.; DOS SANTOS, C. P.; DARRIGAN, G.; HEYDRICH, I; CALLIL, C. T.; CARDOSO, F. R. Primeiros dados quali-quantitativos do mexilhão-dourado, Limnoperna fortunei (Dunker), no Delta do Jacuí, no Lago Guaíba e na Laguna dos Patos, Rio Grande do Sul, Brasil e alguns aspectos de sua invasão no novo ambiente. Revista Brasileira de Zoologia, Curitiba, v. 20, n. 1, p. 75-84, mar. 2003.

MINISTÉRIO DO MEIO AMBIENTE. Plano de Ação Emergencial. Força Tarefa Nacional para Controle do Mexilhão Dourado. Brasília, 2004. Disponível em: <http://www.ibama.gov.br/phocadownload/category/40?download=8159\%3Amexilho>. Acesso em 10 de dez. 2015.

MINISTÉRIO DO MEIO AMBIENTE. Portaria no 494. Força Tarefa Nacional para Controle do Mexilhão Dourado. Brasília, 22 de dezembro de 2003. Disponível em: <http://www.furnas.com.br/arcs/pdf/MexilhaoDourado/Portaria\%20494.2003\%20de\%2022\%20de zembro\%202003.PDF >. Acesso em 10 de dez. 2015.

MPF. Inquérito Civil no 1.34.030.000156/2009-46. 2014. Procuradoria da República em Jales/SP.

OLIVEIRA, José Antônio Puppim de. Desafios do Planejamento em políticas públicas: diferentes visões e práticas. Revista de Administração Pública. Rio de Janeiro. pp. 273/88, 2006. 
OTERO, M., et all. Surveillance des espèces envahissantes marines dans les aires marines protégées (AMP) méditerranéennes : guide pratique et stratégique à l'attention des gestionnaires. 136 pages. UICN. Mijas,Espagne: Solprint, 2013.

ONU. Convenção Internacional sobre Controle e Gestão da Água de Lastro e Sedimentos de Navios. 2004. Disponível em: <http://www.mma.gov.br/estruturas/lastro/_arquivos/lastro36.pdf>. Acesso em 20 de nov. 2015.

PECCATIELLO, Ana Flávia Oliveira. Políticas públicas ambientais no Brasil: da administração dos recursos naturais (1930) à criação do Sistema Nacional de Unidades de Conservação (2000). Desenvolvimento e Meio Ambiente, n. 24, p. 71-82, jul./dez. 2011. Editora UFPR.

RODRIGUES, Marta M. Assumpção. Políticas Públicas. São Paulo: Publifolha, 2013.

SARLET, Ingo Wolfgang; FENSTERSEIFER, Tiago. Princípios do direito ambiental. São Paulo: Saraiva, 2014. 